\title{
AMCProgress
}

\section{Board Approves Position Paper on Medicare Drug Benefit}

$\mathrm{T}$ he Academy of Managed Care Pharmacy (AMCP) has approved a position outlining how it believes a Medicare prescription drug benefit, now under consideration by Congress, should be designed and implemented. The position was approved in October 1999 by AMCP's Board of Directors. A Medicare prescription benefit can improve the quality of care available to older Americans only if the benefit is designed appropriately and is integrated into other facets of the beneficiaries' care, AMCP said.

The Academy believes that prescription drug coverage should be included in all comprehensive health benefit programs. This means that the Medicare program should be reformed to encompass an outpatient prescription drug program. To ensure that the drug benefit is implemented appropriately, pharmaceutical services should be covered, the paper states. These services include not only dispensing the drug but also assessing therapeutic needs, preventing or minimizing adverse drug reactions, developing patient-specific therapy, managing chronic disease, and ensuring that patient care is followed up appropriately.

The most important characteristic of a Medicare drug benefit is its sustainability, AMCP noted. Therefore, Congress must ensure that a Medicare prescription drug benefit is funded in a manner that guarantees its availability on a continuing basis. AMCP believes managed care organizations are best positioned to offer an affordable, quality drug benefit that accomplishes both ends.

The Academy supports the use of one or more alternative funding methods now under consideration:

- using a portion of the budget surplus;

- cost-sharing with beneficiaries;

- proceeds from federal litigation against the tobacco industry or a tax on tobacco products;

- a new general tax initiative; and/or

- a partial offset of savings from phar- maceutical care treatment.

The Medicare benefit also should encourage the use of prudent management tools, the Academy said. Using proven managed care pharmacy tools to deliver a Medicare benefit will help ensure that the benefit will be affordable and will deliver quality care. These tools are:

- Formularies-mechanisms to select safe, effective, and affordable medications that maintain and improve care.

- Pharmaceutical Care-the collaborative efforts of pharmacists, physicians, nurses, and other health professionals to ensure that medications are used appropriately.

- Clinical Guidelines and Step Therapynational or local standards of care to help pharmacists and other health professionals make the best decisions on how to provide patient care for a particular disease or condition. The standards often are set by national health groups, such as the American College of Cardiology, or government agencies, such as the National Institutes of Health.

- Disease State Management-a coordinated process used by the pharmacist and other health professionals to manage and improve the health of a defined population (e.g., patients with asthma) through the course of their disease.

- Drug Use Evaluation-a mechanism of reviewing the way doctors prescribe, pharmacists dispense, and patients use medications.

- Generic Drug Substitution-using equivalent drugs in place of more expensive, brand-name drugs that have the same active ingredients. Consumers generally pay $30 \%$ to $50 \%$ less when buying generic drugs.

- Benefit Design - encouraging prudent use of the benefit by patients, e.g., copayments, coinsurance, or imposition of limitations. For example, copays often encourage patients to choose a lower-priced drug that will be equally effective in treating their disease.

- Academic Detailing-a tool used to improve the appropriateness and cost effectiveness of medication prescribing. Under such programs, pharmacists provide physicians with up-to-date, evidence-based information to encourage the use of cost-effective drug therapy.

The drug benefit also must meet the needs of the over- 65 population, AMCP said. Several issues need consideration. Among these are:

- The high utilization by the elderly of prescription drugs; their need for specific, precise communication about their drugs; and the flexibility needed in designing an appropriate drug benefit.

- The need for the elderly to have their drug therapy coordinated with other aspects of their medical care. This means the drug benefit should be managed by an interdisciplinary medical approach that uses the collaborative efforts of the patient, pharmacist, physician, nurses, and other health care professionals.

A copy of the AMCP Position on Medicare Prescription Drug Coverage is available on AMCP's web site, www.amcp.org and through fax-ondemand (800-964-9648, \#715).

\section{AMCP Revises Web Site, Offers New Look}

AMCP has redesigned its web site (www.amcp.org) to make it easier for members to find information and simpler for them to navigate. The new, more colorful pages feature AMCP's new corporate look. The site highlights current pharmacy-related news, with headlines from the top stories each week. The site also offers many online services, including-for the first time-the ability for members to register online for meetings and conferences. It also allows members to fill out a change-of-address form and 
allows nonmembers to apply for membership online.

The front page contains seven main areas:

- Meetings and Education

- AMCP Resources

- Legislation and Regulatory Affairs

- Membership

- Publications and News

- Corporate Partnership, and

- Career Center

First launched in 1997, the web site has grown dramatically in the last two years. It now contains information about quality issues (including documents from the Pharmacy Quality Council), accreditation standards for residency training in managed care, the Academy's "Where We Stand" position papers, and Concepts in Managed Care Pharmacy (educational papers on key managed care pharmacy issues). Members also can access program information about the Academy's Annual Meeting, its annual educational conference, and other member activities.

In addition, the site continues to offer online the Journal of Managed Care Pharmacy, AMCP News, employment opportunities, and a bookstore of the
Academy's books and periodicals. In the future, the web site will offer continuing education online, provide access to the AMCP member directory, and allow members to view a new student section. Although much of the web page's information is available to the public, many sections are available only to members.

\section{AMCP Launches E-Mail} Mentoring Program

The Academy has launched an innovative mentoring program, connecting student and active members via e-mail. Developed by the Academy's Schools of Pharmacy Relations Committee, the EMail Mentor Program is designed to match active (pharmacist) members with student members interested in managed care. Active members who volunteer as mentors will be assigned one student for the current academic year (September to May). Through this one-to-one program, mentors will be an invaluable resource to students interested in learning about managed care pharmacy, providing them with observations from a working professional. Pharmacists who enjoy helping students will be able to share their professional experiences and enjoy a close mentoring relationship.

During the program's roll-out period, active members who volunteer will be matched at random with student volunteers from one of AMCP's student chapters. As the program gains additional mentors, students who are not affiliated with a chapter also will be able to participate

A set of guidelines has been developed for the program, outlining how it should work. The guidelines say that the mentoring should focus on pharmacy issues, general employment issues, career guidance, and career suggestions, but not on job requests, salary discussions, or letters of recommendation. All e-mail messages should remain confidential between students and mentors. This program is a way for managed care pharmacists to share the knowledge they have about this growing and complex field with students interested in managed care pharmacy. It allows both parties to participate in a convenient and increasingly vital way-via computer. For more information and a copy of the E-mail Mentor guidelines, contact the membership department at 1-800-TAP-AMCP.

\section{Member-Cet-A-Member Cam patse}

Participate in AMCP's 1992-2000 Member-Get-A-Member Campaign and you could win one of these prizes...

\section{* A Canon Elph $490 Z$ APS Camera}

* A JVC EXTD5 Mini Stereo System with CD and Cassette

$\star$ A Pro Staff 11 -Piece Golf Set (Ladies' or Men's set) and Pacesetter Deluxe Golf Bag

Recruit six $(6)$ or more new members and receive . . .

^ A Free Renewal of Your AMCP Membership!

By sponsoring new AMCP members, your efforts contribute to enhancing and strengthening the role of Managed Care Pharmacy. To encourage your colleagues to join AMCP, tell them all about the benefits of membership you receive.

For more information, contact the AMCP Membership Department at 1-800-TAP-AMCP. 